\title{
Physical activity is related to lower levels of pain, fatigue and depression in individuals with spinal-cord injury: a correlational study
}

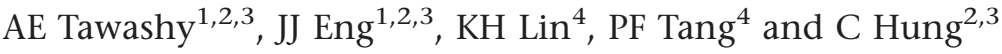 \\ ${ }^{1}$ Rehabilitation Research Lab, GF Strong Rehab Centre, Vancouver, British Columbia, Canada; ${ }^{2}$ Department of Physical Therapy and \\ Graduate Program in Rehabilitation Sciences, University of British Columbia, Vancouver, British Columbia, Canada; ${ }^{3}$ International \\ Collaboration on Repair Discoveries, Vancouver, British Columbia, Canada and ${ }^{4}$ School and Graduate Institute of Physical Therapy, \\ College of Medicine, National Taiwan University, Taipei, Taiwan
}

\begin{abstract}
Study design: This was a prospective cross-sectional study for people with chronic spinal cord injury $(\mathrm{SCl})$.

Objectives: To (1) evaluate the intensity level and nature of physical activity in community-dwelling individuals living with $\mathrm{SCl}$, and (2) explore the relation between descriptive individual variables (for example, lesion level), secondary complications and participation in physical activity.

Setting: Urban community setting.

Methods: A total of 49 subjects with $\mathrm{SCl}$ who used a manual wheelchair for primary mode of mobility (mean years since injury, 11.8; mean age, 43.7 years; $67 \%$ paraplegia) completed the physical activity recall assessment for people with $\mathrm{SCI}$ (PARA-SCI).

Results: Approximately $50 \%$ of reported physical activity among individuals with $\mathrm{SCl}$ is due to activities of daily living. The amount of physical activity was not related to lesion level, age, body mass index or waistline size. Greater heavy-intensity activity was related to lower levels of pain and fatigue and higher levels of self-efficacy, whereas higher amounts of mild-intensity activity and total activity were related to less depressive symptoms.

Conclusions: Activities of daily living are a large component for physical activity among individuals with $\mathrm{SCl}$. It appears that greater physical activity is associated with less secondary complications (pain, fatigue and depression) in individuals with $\mathrm{SCl}$.
\end{abstract}

Spinal Cord (2009) 47, 301-306; doi:10.1038/sc.2008.120; published online 21 October 2008

Keywords: exercise; physical activity; participation; quality of life

\section{Introduction}

Physical activity has the potential to promote health and to enhance quality of life. However, despite the known benefits of physical activity, large proportions of the population are physically inactive to the point that it impacts negatively on health. This is true to an even greater extent for people with spinal-cord injury (SCI). ${ }^{1,2}$

Although physical activity has the potential to reduce the risk of chronic disease after SCI (for example, heart disease, diabetes), the relationship between physical activity and secondary complications has not been established. For example, it is not known whether exercise (for example, wheeling, sports) can reduce pain or depression, or whether

Correspondence: Dr JJ Eng, Department of Physical Therapy and Graduate Program in Rehabilitation Sciences, Rehabilitation Research Lab, University of British Columbia, GF Strong Rehabilitation Centre, Vancouver, British Columbia, Canada V6T 2B5.

E-mail: Janice.Eng@vch.ca

Received 15 April 2008; revised 29 August 2008; accepted 30 August 2008; published online 21 October 2008 activities such as gardening or household chores could have emotional and physical health-enhancing benefits. ${ }^{3}$ Furthermore, little is currently known about which factors can predict the likelihood of someone with SCI performing physical activities. Although the determinants of physical activity among the general population are relatively weak, they are virtually unknown in the SCI population. Although basic mobility function was found to predict physical activity participation in ambulatory individuals with chronic conditions, ${ }^{4}$ no link between injury severity and physical activity participation has been reported within the SCI population. Conditions such as pain, ${ }^{5}$ fatigue, ${ }^{6}$ and depression $^{7}$ have been linked to physical inactivity in both the general population and patients with chronic conditions. However, despite the fact that these conditions are commonly reported after $\mathrm{SCI},{ }^{8}$ their relation to physical inactivity has not yet been explored. In addition, although social support $^{4}$ and self-efficacy ${ }^{9}$ have been shown to influence leisure-time physical activity participation in 
able-bodied individuals, their role within the SCI population is unclear. Given their influence on physical activity participation in the able-bodied population, it would be pertinent to determine the effect of these factors on physical activity participation in individuals with SCI.

Currently, information regarding the type and level of physical activity necessary for positive health outcomes in individuals with SCI is limited. Furthermore, determinants for physical activity among individuals with SCI are relatively unknown. Yet, this information is necessary for developing physical activity guidelines for this population. Therefore, the primary objectives of this cross-sectional study were to (1) evaluate the level and nature of physical activity, (2) determine what demographic factors (for example, sex, age, injury severity) and secondary complications (pain, fatigue and depression) best relate to participation in physical activity, and (3) quantify the roles of social support and self-efficacy in physical activity participation among community-dwelling individuals living with SCI.

\section{Methods}

The study was a prospective cross-sectional design. The inclusion criteria for participation were (1) adults (19 years or older) living in the community; (2) minimum of 1 year since SCI; and (3) use a manual wheelchair for primary mode of mobility. We selected community-dwelling individuals with SCI (rather than those in residential care facilities) who primarily used manual wheelchairs (rather than power wheelchairs) because this group of individuals would more likely have similar opportunities for physical activity. Participants were recruited on a volunteer basis in Taipei, Taiwan. We certify that all applicable institutional and governmental regulations concerning the ethical use of human volunteers were followed during the course of this research.

Participants completed evaluations through standardized assessments and face-to-face interviews led by trained assessors. The study cohort was described with the following demographic information: date of birth, sex, body weight/ height, waistline circumference, American Spinal Injury Association motor score, lesion level and the date of injury. Physical activity was quantified with the physical activity recall assessment for people with SCI (PARA-SCI). Three potential secondary complications after SCI (fatigue, pain and depression), social support and self-efficacy were assessed.

The primary variable of interest was amount of physical activity. Until recently, no valid and reliable self-report measure of physical activity for people with SCI existed. Selfreport physical activity measures developed for the general population are not applicable for the vast majority of individuals with SCI, most of whom use a wheelchair for mobility and expend substantial energy through activities of daily living (ADLs). ${ }^{10}$ Thus, the PARA-SCI was developed. ${ }^{3}$ Briefly, this assessment is administered by a semistructured interview, providing an estimate of time (in minutes) spent participating in mild-, moderate- and heavy-intensity physical activities (Table 1). The PARA-SCI captures three categories of physical activity, namely leisure-time physical activity (activity that one chooses to do during their free time), lifestyle activity (activities that are part of one's daily routine: personal hygiene, household chores, work-related activity $^{2}$ ) and cumulative activity (the combination of leisuretime physical activity and lifestyle activity ${ }^{3}$ ). For the purpose of our study, we further captured two components of lifestyle activity, namely (1) ADLs (self-maintenance tasks, such as bathing, dressing, necessary for meeting the demands of daily living) and (2) household chores (that is, all other household tasks not classified as ADLs). The PARA-SCI is a valid measure of physical activity for individuals with SCI who use a wheelchair as their primary mode of mobility. ${ }^{11}$ Convergent validity of the leisure-time physical activity category has shown that individuals reporting more minutes of moderateand heavy-intensity leisure-time physical activities show better physical fitness (measured by $\mathrm{VO}_{2}$ peak) than those who report fewer minutes of such activities. ${ }^{11}$ Thus, this instrument captures low-level activities (which individuals with a high degree of impairment find physically demanding) that may be overlooked on other scales.

Fatigue, pain and depression were assessed because these are secondary complications that may affect participation in physical activity. ${ }^{5-7}$ The Fatigue Severity Scale was used to quantify the effect of fatigue on daily living, and it is reliable and valid in people with neurological disorders. ${ }^{12}$ The threeitem graded chronic pain questionnaire ${ }^{13}$ was used to assess pain, and it is reliable and valid in people with SCI. ${ }^{14}$ Respondents rate pain's interference with (1) daily activities, (2) ability to participate in recreational, social and family activities and (3) the ability to work (including housework). Depression was measured using the 10-item Centre for Epidemiological Studies-Depression scale (CESD-10), which has been shown to be reliable and valid within the SCI population. ${ }^{8}$

Social support was assessed using the Instrumental Support Evaluation List (ISEL), which measures perceived availability of social resources. ${ }^{15}$ Higher scores indicate better availability of support. Self-efficacy was assessed by the Stanford Selfefficacy for Managing Chronic Disease scale (ESE), six questions that assess participants' confidence in coping with the impact of living with a chronic disease. This scale has been successfully used for individuals with various chronic conditions, including lung and/or heart disease, diabetes and arthritis. $^{16}$

Descriptive characteristics of the cohort were quantified using means, s.d. and frequencies. Scatterplots were generated to ensure there were no outliers or leverage of influential data points. Spearman's correlation coefficients were calculated to determine the strength of the associations between continuous variables because the physical activity variables were not normally distributed (Kolmogorov-Smirnov test). With regard to the PARA-SCI, correlations were computed for cumulative activity and for each intensity level. The influence of categorical variables of sex (male/ female) and lesion level (tetraplegic, paraplegic) on physical activity (three intensity levels) was assessed by $\chi^{2}$ test. All statistical analyses were performed using SPSS v. 13 software (SPSS Inc., Chicago, IL, USA) using a significant level of $P \leqslant 0.05$ (two-tailed). 
Table 1 PARA-SCI classification system

\begin{tabular}{|c|c|c|c|c|}
\hline & Nothing at all & Mild & Moderate & Heavy \\
\hline $\begin{array}{l}\text { How hard are you } \\
\text { working? }\end{array}$ & $\begin{array}{l}\text { Includes activities that } \\
\text { even when you are doing } \\
\text { them, you do not feel like } \\
\text { you are working at all }\end{array}$ & $\begin{array}{l}\text { Includes physical activities } \\
\text { that require you to do very } \\
\text { light work. You should feel } \\
\text { like you are working a little } \\
\text { bit but overall you should } \\
\text { not find yourself working } \\
\text { too hard }\end{array}$ & $\begin{array}{l}\text { Includes physical activities } \\
\text { that require some physical } \\
\text { effort. You should feel like } \\
\text { you are working somewhat } \\
\text { hard but can maintain the } \\
\text { effort for a long time }\end{array}$ & $\begin{array}{l}\text { Includes physical activities } \\
\text { that require a lot of physical } \\
\text { effort. You should feel like } \\
\text { you are working really hard } \\
\text { (almost at your maximum) } \\
\text { and can only do the activity } \\
\text { for a short time before } \\
\text { getting tired. These activities } \\
\text { can be exhausting }\end{array}$ \\
\hline \multicolumn{5}{|l|}{ How does your body feel? } \\
\hline $\begin{array}{l}\text { Breathing and heart } \\
\text { rate }\end{array}$ & Normal & $\begin{array}{l}\text { Stays normal or is only a little } \\
\text { bit harder and/or faster than } \\
\text { normal }\end{array}$ & $\begin{array}{l}\text { Noticeable harder and faster } \\
\text { than normal but not } \\
\text { extremely hard or fast }\end{array}$ & $\begin{array}{l}\text { Fairly hard and much faster } \\
\text { than normal }\end{array}$ \\
\hline Muscles & Normal & $\begin{array}{l}\text { Feel loose, warmed up and } \\
\text { relaxed. Feel normal } \\
\text { temperature or a little bit } \\
\text { warmer and not tired at all }\end{array}$ & $\begin{array}{l}\text { Feel pumped and worked. } \\
\text { Feel warmer than normal } \\
\text { and starting to get tired after } \\
\text { a while }\end{array}$ & $\begin{array}{l}\text { Burn and feel tight and } \\
\text { tense. Feel a lot warmer than } \\
\text { normal and feel tired }\end{array}$ \\
\hline Skin & Normal & $\begin{array}{l}\text { Normal temperature is only a } \\
\text { little bit warmer and not } \\
\text { sweaty }\end{array}$ & $\begin{array}{l}\text { A little bit warmer than } \\
\text { normal and might be a little } \\
\text { sweaty }\end{array}$ & $\begin{array}{l}\text { Much warmer than normal } \\
\text { and might be sweaty }\end{array}$ \\
\hline Mind & Normal & $\begin{array}{l}\text { You might feel very alert. Has } \\
\text { no effect on concentration }\end{array}$ & $\begin{array}{l}\text { Requires some concentration } \\
\text { to complete }\end{array}$ & $\begin{array}{l}\text { Requires a lot of } \\
\text { concentration (almost full) } \\
\text { to complete }\end{array}$ \\
\hline
\end{tabular}

Abbreviation: PARA-SCI, physical activity recall assessment for patients with spinal cord injury.

Modified from Martin Ginis et al. ${ }^{3}$

Table 2 Demographic information and PARA-SCI results

\begin{tabular}{|c|c|c|c|c|c|c|c|c|c|c|}
\hline & \multicolumn{3}{|c|}{ Para-SCl activity } & \multicolumn{7}{|c|}{ Demographic information } \\
\hline & $\begin{array}{l}\text { Intensity } \\
\text { level }\end{array}$ & $\mathrm{N}$ & Minutes & $\begin{array}{c}\text { Age } \\
\text { (years) }\end{array}$ & $\begin{array}{l}\text { Duration } \\
\text { of injury } \\
\text { (years) }\end{array}$ & $\begin{array}{c}\text { Paraplegia } \\
\text { (\%) }\end{array}$ & $\begin{array}{c}\text { Complete } \\
\text { injuries } \\
\text { (\%) }\end{array}$ & $\begin{array}{l}\text { ASIA motor } \\
\text { score }\end{array}$ & $\begin{array}{c}\text { Body mass } \\
\text { index } \\
\left(\mathrm{kg} / \mathrm{m}^{2}\right)\end{array}$ & $\begin{array}{c}\text { Waist } \\
\text { circumference } \\
(\mathrm{cm})\end{array}$ \\
\hline \multirow[t]{3}{*}{ All subjects } & Mild & 49 & $135.8(177.9)$ & & & & & & & \\
\hline & Moderate & 49 & $81.5(149.4)$ & $43.7(11.7)$ & $11.8(9.2)$ & 67 & 61 & 50.65 (14.9) & $24.0(5.0)$ & 89.3 (13.6) \\
\hline & Heavy & 49 & $16.5(30.0)$ & & & & & & & \\
\hline \multirow[t]{3}{*}{ Subgroups } & Mild & 47 & $135.8(177.9)$ & $43.4(11.7)$ & $11.6(9.0)$ & 70 & 60 & $51.62(14.4)$ & $24.1(5.1)$ & $89.5(13.7)$ \\
\hline & Moderate & 33 & $108.0(119.3)$ & $42.7(12.1)$ & $10.9(8.2)$ & 70 & 67 & $49.42(15.4)$ & $24.2(4.6)$ & $88.6(14.1)$ \\
\hline & Heavy & 15 & $53.7(34.1)$ & $47.2(10.5)$ & $12.7(9.1)$ & 60 & 53 & $51.47(16.4)$ & $23.6(4.8)$ & $85.6(13.9)$ \\
\hline
\end{tabular}

Abbreviations: ASIA, American Spinal Injury Association; PARA-SCI, physical activity recall assessment for patients with spinal cord injury.

Demographic information and PARA-SCI results are reported (in minutes) and presented for 'all subjects' (top row) (i.e., included even if they reported 0 min of activity in that intensity category) and for 'subgroups' who reported participating in each intensity level of activity (i.e., those participants who recorded $>0$ min of activity in that intensity category).

This table highlights that participant demographics are similar across all exercise intensity levels.

Mean values are reported with standard deviations in parentheses.

\section{Results}

A total of 49 people with SCI were assessed. Subject characteristics are reported in Table 2. Measures of pain, depression, fatigue, social support and self-efficacy are presented in Table 3.

Forty-seven subjects reported participating in mild-intensity activity, whereas 33 and 16 subjects reported participating in moderate- and heavy-intensity activities, respectively (Table 2). Approximately 50\% of all heavy- and moderateintensity physical activities included lifestyle tasks (Table 4). Specifically, ADLs made up $96 \%$ of the time spent doing heavy- or moderate-intensity lifestyle tasks.
One participant was noted to be an outlier in correlations with heavy-intensity physical activity with values greater than two standard deviations from the mean. Subsequent calculations confirmed the subject's data points to have unacceptable leverage (leverage score was $0.27^{17}$ ), supporting the removal of this subject from correlations with heavy intensity.

No significant correlations were found between physical activity and any demographic factors. $\chi^{2}$ Tests did not reveal any influence of sex or lesion level on physical activity participation. However, physical activity was significantly related to secondary complications (Table 5). Specifically, high amounts of heavy-intensity physical 
activity corresponded with (1) lower levels of fatigue; (2) higher levels of self-efficacy and (3) lower levels of pain. As an example, the scatterplot of heavy physical activity versus fatigue is highlighted in Figure 1. Higher amounts of mildintensity physical activity correlated with (1) lower levels of pain;

(2) higher levels of social support and (3) lower levels of depression, whereas moderate physical activity did not correlate with any factors. Lastly, more total physical activity was related to higher self-efficacy and less depression.

The removal of one participant from correlations with heavy-intensity physical activity participation had minimal

Table 3 Measures of secondary complications (FSS, GCP and CESD-10), social support (ISEL) and self-efficacy (ESE)

\begin{tabular}{lcc}
\hline Measure & Score & Range \\
\hline ISEL (maximum = 48) & $29.1(8.3)$ & $7.0-45.0$ \\
Stanford self-efficacy for & $6.5(1.6)$ & $2.0-10.0$ \\
managing chronic disease scale & & \\
(ESE) (maximum $=10)$ & $4.1(1.2)$ & $1.4-6.6$ \\
FSS (maximum $=7.0)$ & $3.7(2.8)$ & $0.0-9.33$ \\
GCP questionnaire & & \\
(maximum $=10$ ) & $11.0(6.8)$ & $1.0-27.0$ \\
CESD-10 scale (maximum = 30)
\end{tabular}

Abbreviations: CESD, Centre for Epidemiological Studies-Depression; FSS, fatigue severity scale; GCP, graded chronic pain; ISEL, Instrumental support evaluation list.

Mean scores are presented with standard deviations in parentheses.

Higher scores for FFS, GCP and CESD-10 indicate greater impairment. Higher scores for ISEL and ESE indicate better scores.

Table 4 Average percentage of the total time doing each of heavy- and moderate-intensity physical activities

\begin{tabular}{lcc}
\hline $\begin{array}{l}\text { Type of } \\
\text { physical activity }\end{array}$ & $\begin{array}{c}\text { Heavy intensity } \\
(\mathrm{n}=15)(\%)\end{array}$ & $\begin{array}{c}\text { Moderate intensity } \\
(\mathrm{n}=33)(\%)\end{array}$ \\
\hline Lifestyle activity & 59 & 49 \\
$\quad$ ADLs & 59 & 45 \\
$\quad$ Chores & 0 & 4 \\
Leisure-time physical & 41 & 51 \\
activity & & \\
$\quad$ Exercise & 19 & 37 \\
$\quad$ Other & 22 & 14 \\
\hline
\end{tabular}

Abbreviation: ADL, activity of daily living.

For example, on average, exercise makes up $19 \%$ of total heavy-intensity physical activity. effects on the pain and fatigue analysis (both remained significant at $P<0.01$ and $P<0.001$, respectively). However, removing the high leverage data point for the correlation between self-efficacy and heavy-intensity physical activity caused the correlation co-efficient to increase from 0.437 $(P=0.091)$ to $0.656(P=0.008)$.

\section{Discussion}

This study provides an evaluation of the level and nature of physical activity among a cohort of individuals with SCI. Secondly, we provide novel data highlighting the relationships between physical activity participation and secondary complications in this group.

Demographic variables were consistent with the general SCI population. ${ }^{18}$ Mean scores on the Fatigue Severity Scale and CESD-10 suggest that our participants were experiencing mild fatigue ${ }^{12}$ and mild depression, ${ }^{19}$ whereas scores on the three-item graded chronic pain and ESE reflected fairly low levels of pain-related disability ${ }^{13}$ and relatively high levels of perceived disease-management self-efficacy. ${ }^{16}$

Physical activity participation in this cohort was similar to earlier investigations using the PARA-SCI. ${ }^{3,11}$ Most of our

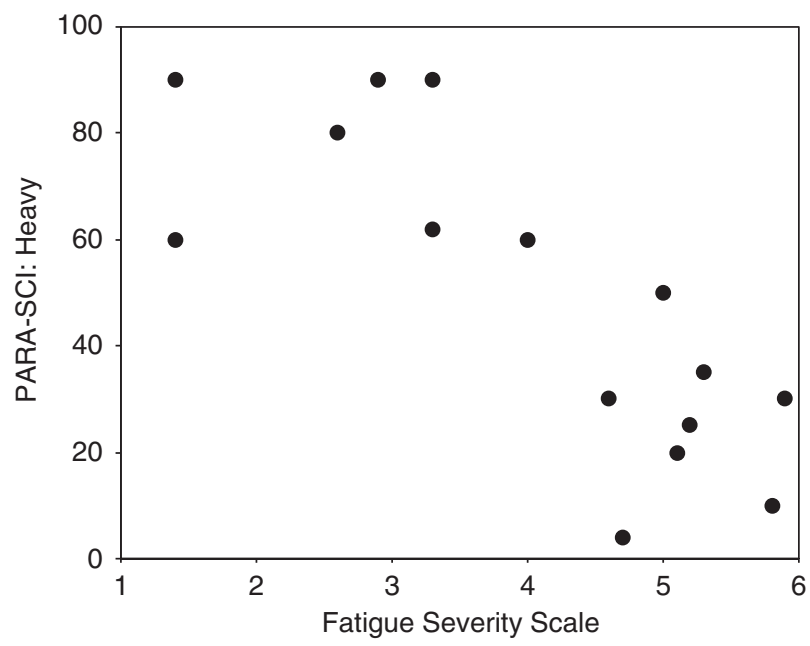

Figure 1 Scatterplot highlighting heavy physical activity (PARA$\mathrm{SCl}$ ) vs fatigue (Fatigue Severity Scale) for 15 participants with $\mathrm{SCI}$ $(r=-0.767 ; P<0.001)$.

Table 5 Heavy- and mild-intensity physical activities are related to secondary complications and personal factors

\begin{tabular}{|c|c|c|c|c|c|c|}
\hline & & Fatigue severity scale & Self-efficacy & $G C P$ & ISEL & $C E S-D$ \\
\hline \multirow{2}{*}{ PARA-SCI: heavy $(n=15)$} & Pearson's correlation & -0.767 & 0.656 & -0.612 & 0.478 & -0.270 \\
\hline & Significance (two-tailed) & $0.001^{* *}$ & $0.008^{* *}$ & $0.015^{*}$ & 0.072 & 0.331 \\
\hline \multirow[t]{2}{*}{ PARA-SCI: moderate $(n=33)$} & Pearson's correlation & -0.164 & 0.295 & -0.132 & -0.099 & -0.100 \\
\hline & Significance (two-tailed) & 0.361 & 0.095 & 0.464 & 0.582 & 0.580 \\
\hline \multirow[t]{2}{*}{ PARA-SCI: mild $(n=47)$} & Pearson's correlation & -0.001 & 0.253 & -0.294 & 0.312 & -0.565 \\
\hline & Significance (two-tailed) & 0.994 & 0.086 & $0.045^{*}$ & $0.033^{*}$ & $0.0001^{* *}$ \\
\hline \multirow{2}{*}{ PARA-SCI: total $(n=49)$} & Pearson's correlation & -0.103 & 0.288 & -0.266 & 0.185 & -0.318 \\
\hline & Significance (two-tailed) & 0.481 & $0.045^{*}$ & 0.064 & 0.203 & $0.026^{*}$ \\
\hline
\end{tabular}

Abbreviation: PARA-SCI, physical activity recall assessment for patients with spinal cord injury.

Correlations are noted as ${ }^{*} P<0.05$, and ${ }^{* *} P<0.01$. 
participants stated doing some mild physical activity, yet less than two-thirds reported moderate levels of exertion and only a third reported heavy levels of exertion. Similarly, high levels of inactivity, as measured by heart rate monitors over a 3-day period, were earlier documented in a group of individuals with paraplegia. ${ }^{2}$ In our study, ADL tasks were responsible for approximately 50\% of time spent doing moderate- and heavy-intensity activities, supporting the preexisting notion that lifestyle activity can be particularly taxing for individuals with SCI. ${ }^{10}$

Surprisingly, demographic factors such as age, injury duration or lesion level (paraplegic/tetraplegic) were not related to physical activity participation. Although Dearwater et al. ${ }^{1}$ suggested that people with paraplegia were more active than those with tetraplegia, their data came from a diverse sample from an in-patient rehabilitation setting. Our sample included only adult manual wheelchairs users living in the community, where secondary complications and environmental factors would more likely influence physical activity participation.

Reduced secondary complications were related to the amount of physical activity. Our finding that greater participation in mild-intensity activity relates to decreased secondary complications supports evidence that very sedentary people may derive health benefits from low intensities of activity.

Our results showed that heavy-intensity activity was strongly correlated with measures of fatigue, pain and self-efficacy. As our results are correlational, no causality can be inferred. It is possible that lower levels of secondary complications such as fatigue and pain allow one to participate more effectively in heavy-intensity physical activity. Alternatively, the engagement in physical activity may prevent or reduce the occurrence of secondary complications.

The relationship between self-efficacy and physical activity may be more complex. People who have higher beliefs in their abilities to perform exercise are more likely to participate in intense leisure-time physical activity. ${ }^{9}$ Similarly, those with higher beliefs in their abilities to perform lifestyle activities may be more likely to accomplish ADLs as independently as possible, thereby rating these tasks as high intensity. Conversely, the ability to exercise and perform lifestyle activities may positively influence one's self-efficacy in managing his/her condition. Removing one outlying participant strengthened the correlation between heavyintensity activity participation and self-efficacy, suggesting this participant did not experience a similar relationship between these entities.

The positive correlation between social support and physical activity found in this study supports that of previous research in other populations. Social support was positively related to 7 days of accelerometer measurement in individuals with multiple sclerosis. ${ }^{20}$ Using the social cognitive theory, these authors proposed that social support was associated with physical activity because of an intermediary relationship with self-efficacy (that is, social support correlated with physical activity because both serve as a source of efficacy information). This theory may have merit for our group as post hoc analyses showed strong positive correlations between social support and self-efficacy.

\section{Limitations}

This was a cross-sectional observational investigation; therefore, we cannot interpret any causality from the results. A multiple regression analysis was not performed to predict physical activity because although heavy activity was related to several variables, only a small number of subjects $(n=16)$ reported participating in heavy activity. Furthermore, because of our small sample size, one outlier was overly influential on our results and was removed from correlations involving heavy-intensity physical activity. Lastly, by using a $P$-value of 0.05 , our study (which involved 20 correlations) would have a chance that, at a maximum, one correlation may be significant by chance alone.

\section{Conclusions}

Although there are a number of potential barriers to participating in physical activity, some people with SCI do adopt a physically active lifestyle. Demographic factors measured in this study (sex, age, time since injury and lesion level) were not determinants of physical activity. Rather, these data highlight that secondary complications (pain, fatigue) are barriers, whereas self-efficacy is a facilitator to physical activity participation. Furthermore, performance of activities that were not necessarily physically taxing was related to decreased secondary complications. Ultimately, this study reinforces that physical activity is a complex issue for individuals with SCI. Further research needs to be conducted to better understand the predictors of physical activity participation for this population.

\section{Acknowledgements}

We thank Dr Yen-Ho Wang, Mrs Yueh-Er Lee and Ms Zu-Si Lei for subject recruitment; Ms Ron-Jyuan Liing, Ms Yin-Chen Chen and $\mathrm{Mr}$ Li-Hsueh Chen for data collection; the National Science Council (no. NSC 96-2811B-002-001, Taiwan) and the International Collaboration on Repair Discovery for visiting professor awards (to JJE) and Canadian Institutes for Health Research and the Michael Smith Foundation for Health Research for career scientist awards (to JJE).

\section{References}

1 Dearwater SR, LaPorte RE, Cauley JA, Brenes G. Assessment of physical activity in inactive populations. Med Sci Sports Exerc 1985; 17: 651-655.

2 Buchholz AC, McGillivray CF, Pencharz PB. Physical activity levels are low in free-living adults with chronic paraplegia. Obes Res 2003; 11: 563-570.

3 Martin Ginis KA, Latimer AE, Hicks AL, Craven BC. Development and evaluation of an activity measure for people with spinal cord injury. Med Sci Sports Exerc 2005; 37: 1099-1111.

4 Ashe MC, Eng JJ, Miller WC, Soon JA. Disparity between physical capacity and participation in seniors with chronic disease. Med Sci Sports Exerc 2007; 39: 1139-1146.

5 Rosemann T, Kuehlein T, Laux G, Szecsenyi J. Osteoarthritis of the knee and hip: a comparison of factors associated with physical activity. Clin Rheumatol 2007; 26: 1811-1817. 
6 Rosqvist E, Heikkinen E, Lyyra TM, Hirvensalo M, Kallinen M, Leinonen $\mathrm{R}$ et al. Factors affecting the increased risk of physical inactivity among older people with depressive symptoms. Scand J Med Sci Sports 2008 (e-pub ahead of print).

7 Galper DI, Trivedi MH, Barlow CE, Dunn AL, Kampert JB. Inverse association between physical inactivity and mental health in men and women. Med Sci Sports Exerc 2006; 38: 173-178.

8 Miller WC, Anton HA, Townson AF. Measurement properties of the CESD scale among individuals with spinal cord injury. Spinal Cord 2008; 46: 287-292.

9 Cerin E, Vandelanotte C, Leslie E, Merom D. Recreational facilities and leisure-time physical activity: an analysis of moderators and self-efficacy as a mediator. Health Psychol 2008; 27: S126-S135.

10 Janssen TW, van Oers CA, van der Woude LH, Hollander AP. Physical strain in daily life of wheelchair users with spinal cord injuries. Med Sci Sports Exerc 1994; 26: 661-670.

11 Latimer AE, Martin Ginis KA, Craven BC, Hicks AL. The physical activity recall assessment for people with spinal cord injury: validity. Med Sci Sports Exerc 2006; 38: 208-216.

12 Herlofson K, Larsen JP. Measuring fatigue in patients with Parkinson's disease - the Fatigue Severity Scale. Eur J Neurol 2002; 9: 595-600.
13 Von Korff M, Ormel J, Keefe FJ, Dworkin SF. Grading the severity of chronic pain. Pain 1992; 50: 133-149.

14 Raichle KA, Osborne TL, Jensen MP, Cardenas D. The reliability and validity of pain interference measures in persons with spinal cord injury. J Pain 2006; 7: 179-186.

15 Cohen S, Mermelstein R, Kamarck T, Hoberman HM. Measuring the functional components of social support. In: Sarason IG, Sarason BR (eds). Social Support: Theory, Research, and Applications. Martinus Nijhoff: The Hague, Netherlands. 1985, pp 73-94.

16 Lorig KR, Sobel DS, Ritter PL, Laurent D, Hobbs M. Effect of a selfmanagement program on patients with chronic disease. Eff Clin Pract 2001; 4: 256-262.

17 Pallant J, Pallant JF. In: SPSS Survival Manual: A Step by Step Guide to Data Analysis Using SPSS. Allen \& Unwin, Open University Press: Berkshire, UK, 2007.

18 Ackery A, Tator C, Krassioukov A. A global perspective on spinal cord injury epidemiology. J Neurotrauma 2004; 21: 1355-1370.

19 Boey KW. Cross-validation of a short form of the CES-D in Chinese elderly. Int J Geriatr Psychiatry 1999; 14: 608-617.

20 Motl RW, Snook EM, McAuley E, Scott JA, Douglass ML. Correlates of physical activity among individuals with multiple sclerosis. Ann Behav Med 2006; 32: 154-161. 